\title{
Projetos nas escolas: uma política de secundarização da especificidade do trabalho escolar
}

\author{
Projects in schools: a sidelined policy of the school work \\ specificity
}

\section{Cristina Cardoso'}

\section{Resumo:}

O presente estudo analisou projetos e seu impacto na organização do trabalho pedagógico nas escolas de Araucária. A presença de projetos nas escolas demonstrou que estes promovem a fragmentação do trabalho pedagógico e secundarizam o acesso ao conhecimento erudito. Os projetos são resultado da pulverização das políticas públicas que substituem o planejamento por uma lista de projetos com ações pontuais, o que abre espaço para atuação de empresas e ONGs na escola, com interesses antagônicos aos dos filhos da classe trabalhadora.

Palavras-Chave: Políticas Públicas; Projetos; Educação Básica.

\begin{abstract}
:
This study analyzed projects and their impact on the organization of educational work in schools in Araucaria-PR, Brazil. The presence of projects in schools has shown that they promote the fragmentation of the pedagogical work and the harm access to knowledge learned. The projects are the results of spraying of public policy wich replace the planning by a list of projects with specific actions, which opens space for performance of companies and NGOs in school, with interests antagonistic to those of the children of the working class.
\end{abstract}

Keywords: Public Policies; Projects; Basic Education. 


\section{Introdução}

Este trabalho de pesquisa investigou e analisou a presença, possíveis consequências, a gênese, os interesses e o contexto do desenvolvimento de projetos nas escolas municipais de AraucáriaPR. Esses projetos são propostos por várias instituições, órgãos e também pelo terceiro setor, como, por exemplo, a Secretaria de Educação do município, o Ministério da Educação, empresas e organizações não-governamentais, e alguns são criados até nas próprias escolas. Tais projetos não são parte integrante do currículo escolar e, via de regra, estabelecem uma forçada relação com os conteúdos escolares.

Como pedagoga da rede municipal de Araucária, tenho convivido com a proposição crescente de atividades, programas, vendas de produtos e serviços e projetos com pretensão de se estabelecerem como pedagógicos. São tantas as proposições e tarefas colocadas ou sugeridas para escola que durante a pesquisa, em entrevista, uma pedagoga desabafou:

"é muito programa na escola, além disso, ainda tem que fazer plano de ação, projeto político pedagógico e mais esses tantos projetos, temos que administrar a falta de professores. Tem as ações do governo que vêm para escola para gente fazer (...) Nós parecemos um depósito onde tudo se descarrega e por isso não temos tempo para os nossos projetos pedagógicos, para acompanhar de perto a alfabetização, por exemplo.....2 (informação verbal)

Foi exatamente um sentimento semelhante ao demonstrado pela pedagoga que despertou meu interesse de pesquisar sobre o assunto. Nos últimos anos, além das tarefas, começaram a aparecer muitos "projetos", com diferentes temáticas, formas e origens. Embora não se possa denominar, a rigor, todas essas atividades ou ações como projetos, esta terminologia é utilizada pelos professores para indicar as atividades que extrapolam as que rotineiramente executam em sala de aula. Partindo dessas atividades, este trabalho investigou aqueles que se constituem propriamente em projetos.
Entretanto, como o termo "projeto" é usualmente aplicado a atividades de diversas naturezas, abre-se um leque de possibilidades de pesquisa impossível de ser esgotado neste trabalho. As principais categorias utilizadas no desenvolvimento desta pesquisa foram a fragmentação e a totalidade, a centralidade e a descentralização, presentes no trabalho da escola. Para melhor compreender como se entendem tais categorias no trabalho da escola, é necessário esclarecer qual é a concepção pedagógica em que se assenta este trabalho de pesquisa.

\section{A concepção pedagógica em que se assenta este trabalho de pesquisa}

A intenção aqui não é criar uma nova concepção de educação, mas, ao revisitar autores como Snyders, Suchodolski, Gramsci, Makarenko, Saviani, entre outros, estabelecer um marco conceitual claro para e a partir dele construir o diálogo com a realidade das escolas pesquisadas.

Cabe à escola dar condições para que o aluno conheça outras possibilidades além das que a sua condição de classe the oportunizou. A educação escolar deve exercer um papel de superação, possibilitando ao aluno a compreensão não apenas das condições individuais, mas sobretudo do caráter excludente de uma sociedade dividida em classes, bem como o horizonte da sua transformação: uma sociedade em que todas as pessoas tenham acesso aos bens sociais e culturais produzidos pela humanidade. Possibilitar esta compreensão é realizar a associação, apresentada por Suchodolski (1976), entre uma proposta emancipadora de educação e a definição de uma sociedade mais justa e igualitária.

A construção de um projeto de sociedade passa pela aquisição de conhecimentos históricos e científicos, e, para tanto, a escola é indispensável. Por isso, as crianças não podem sozinhas tomar consciência das suas aspirações, não podem aprender sozinhas a entender o mundo e seus mecanismos de exclusão nem sempre claros. Para que de fato aprendam, os 
professores devem ensinar. Além disso, quando o professor toma posicionamento, ajuda a criança a distinguir a verdade do erro.

Por outro lado, não se pretende desrespeitar a criança, desconsiderá-la ou ignorar que cada fase de desenvolvimento humano tem suas características e necessidades e que, portanto, o profundo conhecimento científico do professor sobre os conteúdos a serem trabalhados deve ser inseparável do conhecimento sobre os sujeitos com quem se vai trabalhar e das formas de ensinar, que nem sempre precisam ser "apoteóticas" e repletas de "criatividade", mesmo porque nem todos os dias em todos os momentos isso é possível. A escola básica deve assegurar, inclusive, a aquisição de hábitos e automatismo.

\section{Desenvolvimento}

Os dez projetos existentes nas escolas do município de Araucária são, do ponto de vista metodológico, os marcos de partida e de chegada desta pesquisa. Não se trata, no entanto, de discutir um problema existente na escola apenas por ela mesma. Seria ingenuidade achar que este poderia ser resolvido ou entendido apenas olhando o interior da escola. Como já escreveu Tavares: "Quando alunos e professores iniciam uma aula qualquer em alguma escola pública, as condições do que se pode ensinar e aprender estão definidas pela interferência de um conjunto de instâncias que estão muito além do que se pode alcançar ao olhar o cotidiano escolar". (2004, p.1)

Optou-se por iniciar a busca da origem da utilização de projetos na escola, pelos primeiros autores que escreveram, de forma significativa, sobre o ensino por projetos ou equivalentes, como os centros de interesses que se dão no movimento da Escola Nova, com Montessori e Decroly, até os mais recentes, de origem espanhola, datados da década 80 do século passado, bem como a sua disseminação mais efetiva no Brasil.

O trabalho com projetos na escola foi inicialmente desenvolvido sob os princípios da Escola Nova. Sem dúvida, um trabalho vivo e interessante, que demonstra um importante princípio desse movimento pedagógico: o aluno como sujeito do ato de ensinar e aprender. Fica claro também que, para desenvolver um trabalho pedagógico baseado nos princípios da Escola Nova, eram necessárias algumas condições materiais, tais como menor número de alunos em sala, mais e diversificados materiais.

Ao investigar a raiz mais recente dos projetos postos nas escolas atualmente, percebese que sua origem possivelmente está na reforma da escola espanhola. Nos anos 80 do século passado, algumas escolas espanholas reformaram seus currículos, com o trabalho pedagógico organizado a partir de projetos.

Entre as reflexões que Hernández; Monserrat (1998) fazem para exemplificar a proposta de trabalho com projetos, pode-se apontar resumidamente: a importância da diversidade de temas, um quadro de profissionais fixos na escola, muito tempo para estudos e reflexões por parte dos professores, a presença e participação dos pais na escola e na vida escolar dos filhos e diversos materiais à disposição.

Dessa forma, o quadro que se desenha é que as condições materiais, de trabalho e de formação docente, são determinantes para que se possa pensar em um trabalho pedagógico de qualidade. No contexto das escolas públicas brasileiras, uma proposta como essa, que possivelmente tenha dado certo na realidade espanhola, pode ser desastrosa, uma vez que as condições apontadas pelos proponentes como indispensáveis para o desenvolvimento do trabalho não se encontram nas escolas pesquisadas. Reiteram-se, aqui, as críticas apontadas à Escola Nova.

A Pedagogia de Projetos no Brasil foi desenvolvida por autores como Nilbo Ribeiro Nogueira, mestre em psicopedagogia pela USP. A proposta preconizada por esse autor é o trabalho interdisciplinar para desenvolver as inteligências múltiplas.

Além do livro de Nogueira(2001), selecionaramse para análise duas obras lançadas em 2006; a primeira intitulada "A Metodologia de Ensino por Projetos", da autora Gisele do Rocio Cordeiro Mugnol dos Santos, e a segunda, "Trabalhando com projetos: planejamento e gestão de projetos educacionais", de Dácio G. Moura e Eduardo F. Barbosa. No primeiro livro, direcionado para o curso normal superior, a autora afirma fazer 
uma contextualização histórica das pedagogias tradicional, escolanovista e tecnicista, e apresenta o que ela chama de paradigmas emergentes. São esses a pedagogia holística, a pedagogia progressista e ensino por pesquisa. Após apresentar tais pressupostos, afirma ser necessário, a fim de encontrar a melhor forma de ensinar, "(...) formar uma teia, uma rede contendo ensinamentos de cada um deles (...)" (SANTOS, 2006, p. 42), e a partir disso propõe o ensino por projetos. No seu entendimento:

Ametodologia por projetos tem como finalidade contemplar as aprendizagens recomendadas pela Unesco para a educação no século XXI, ou seja, aprender a conhecer, aprender a fazer, aprender a ser; aprender a conviver. Em resumo, assim se definem essa aprendizagem (...) É o fazer com criatividade e autonomia desenvolvendo aptidões para atuar na profissão com mais competência e habilidade. (SANTOS, 2006, p. 55-56)

A segunda dessas publicações é uma proposta de trabalho com projetos na escola direcionada para o ensino médio e é uma adaptação das áreas de administração e engenharia. Para validar a utilização de tal proposta, os autores citam órgãos nacionais e internacionais que apoiam projetos para o desenvolvimento cultural, científico, educacional e econômico, como a UNESCO e o Banco Mundial ${ }^{3}$

Pode-se perceber, ao longo do livro, que a proposta apregoada é uma espécie de treinamento para um futuro emprego, dada a semelhança do modelo de organização dos projetos na escola com os das empresas. Por exemplo: para atingir metas, algumas empresas utilizam um quadro informando os prazos e os números de produção, tal como a proposta pedagógica utilizaria quadros estabelecendo tempo e objetivos para o desenvolvimento dos projetos, nos moldes dos projetos empresariais.

A idéia de desenvolver alunos autônomos não é, por si só, ruim. Para as crianças que tinham possibilidades de experiências intelectuais fora da escola, era uma oportunidade de criar ou ampliar a autonomia. Entretanto, para os alunos sem nenhum contato intelectual ou acadêmico fora da escola e que nela tinham a única oportunidade de aprender os conteúdos e as formas escolares, essa dificuldade tinha grandes probabilidades de se aprofundar. A falta dessas condições (o que frequentemente ocorre na escola pública) pode resultar em consequências desastrosas, como se pode constatar.

As características de organização do trabalho escolar por projetos pedagógicos - presentes tanto na época do movimento da Escola Nova como na reforma da escola espanhola nos anos 80 e 90 do século passado - têm tido alguns princípios e idéias importados para o Brasil e encontram alguns limites contextuais.

Nas condições sociais e educacionais brasileiras, a implementação de projetos nos quais se leva em consideração o desenvolvimento individual e a autonomia de cada aluno pode resultar em um impacto duvidoso, na medida em que existe uma desigualdade social de imensas proporções. Embora a condição social dos alunos não possa ser empecilho para que eles aprendam, tampouco pode ser ignorada; elas são reais e ignorá-las é um forte indício de conservadorismo e de manutenção da conjuntura vigente.

Portanto, duas preocupações centrais se põem ao pensar a organização do currículo escolar por projetos de trabalho no Brasil: uma é a possibilidade de diminuição dos conteúdos; a outra, a organização ficar entregue ao espontaneísmo.

Os projetos são também reflexo de um modelo de políticas públicas para educação, não mais pautado em um planejamento contínuo. Este tipo de gestão tem sido substituído paulatinamente por ações pontuais, como os programas de incentivo à leitura, de dinheiro direto na escola, formação de dirigentes municipais, entre outros. Além desses programas relacionados à administração, existem aqueles ligados a temas emergenciais, como prevenção às drogas, educação sexual, respeito

3 Não se pode ignorar como o próprio nome identifica que o Banco Mundial é um Banco, portanto uma instituição financeira, logo, não existe entre os seus interesses o desejo da emancipação da classe que vive do trabalho, uma vez que é uma instituição capitalista e como o capitalismo tem em sua natureza a exploração dessa classe é contrária aos interesses da sua manutenção e sobrevivência a emancipação dos despossuídos. 
às diferenças. Assim, tanto as políticas públicas para a educação como as ações diárias das escolas são realizadas na forma de uma lista de tarefas a se cumprir. Com isso, nem os envolvidos podem ter a clareza do que se pretende com a realização destas em longo prazo.

Não seria exagero afirmar que, ao adotar projetos diversos, cria-se uma "política de pulverização", ou seja, um currículo que pulveriza o conhecimento científico, empobrecendo a sua aquisição por meio de inúmeros projetos, por exemplo, combate às drogas, campanhas contra doenças, exame oftalmológico e de audição. Dessa forma, propiciam-se uma fragmentação e uma diminuição dos conteúdos escolares, ${ }^{4}$ porque estes vão sendo cada vez mais deixados de lado.

A escola torna-se progressivamente refém desses projetos. Daí a necessidade de que sejam criteriosamente avaliados, para que possamos saber em que medida eles têm se constituído em uma receita para transformar a escola em uma espécie de "escolinha de contenção da barbárie".

A disseminação de "projetos" na escola tem sido justificada pela crescente ênfase nas propostas de organização de currículo por projetos de trabalho ou de pesquisa, ou, como outros autores chamam, o trabalho na escola por projetos. Tem ocorrido a divulgação de uma série de propostas, tanto para o trabalho escolar como no âmbito da gestão de ensino, que utilizam o termo "projeto", dando legitimidade às atividades que assim se denominam e que ocorrem paralelamente ou no lugar daquelas vinculadas ao currículo.

\section{O impacto dos projetos nas escolas}

A pesquisa foi desenvolvida por meio de entrevistaseanálises de documentos duranteoano de 2006. Entrevistaram-se algumas pessoas que trabalham na Secretaria Municipal de Educação de Araucária e nas escolas do município. As entrevistas nas escolas foram realizadas em dois momentos. No primeiro momento, nas escolas do perímetro urbano do município que atendem de pré à oitava série do ensino fundamental. Num segundo momento, dessas 31 escolas selecionaram-se duas, que melhor representam o contexto para aprofundamento da pesquisa.

Optou-se por investigar três dos dez projetos presentes em duas escolas: um proposto pela mantenedora, um segundo proposto pela iniciativa privada, na forma de organização não-governamental, e o último idealizado e desenvolvido pelas próprias escolas.

Se, ao investigar as duas escolas, olharmos apenas no seu interior, somente encerrada em seus muros, estas podem ser consideradas bem diferentes. Entretanto, se, ao analisarmos, levarmos em consideração os determinantes existentes para além de seus muros, é possível perceber que não são tão diferentes como se pode pressupor: o que as diferencia, na verdade, é a profundidade dos problemas postos pelas desigualdades sociais; portanto, as escolas não são diferentes entre si, são desiguais, e nenhuma delas escapa às condições e aos limites resultantes da precariedade que vivem hoje todas as escolas públicas do município pesquisado e de outros municípios brasileiros.

A presença de um grande número de projetos nas escolas nos indica a ausência da clareza da função da própria escola - ou da massificação que sofre -, pois a todo instante tem que resolver problemas emergenciais para continuar funcionando, como os problemas de indisciplina e violência, os quais se pretende amenizar com o desenvolvimento do projeto de valores.

A angústia que gera esse projeto é genuína, sobretudo se considerarmos que Bara e Ribeiro, empesquisarealizadaaindaem 1996, constataram que, quanto maior o grau de concentração de renda, maiores as taxas de homicídio. Somam-se a isso os dados do IBGE de 2000, que apontam 
os homicídios, principalmente com arma de fogo, como principal causa de óbito entre jovens de 15 a 24 anos a partir dos anos 90.5

Por isso, na escola "A", uma escola central, o projeto de valores não está presente de forma tão sistemática e evidente, mas a escola não ignora o problema da violência, reconhece-o e o vive em menor gravidade e urgência, daí porque o projeto de valores é organizado de forma menos intensiva. Se fosse grave o problema, se atingisse mais diretamente o trabalho da escola, e supondo que o projeto considerado para o trabalho de valores resolvesse o problema, tal projeto não poderia atingir somente os melhores alunos da escola, ao contrário, o critério de participação (que é o da não ocorrência disciplinar e média acima de 7 (sete) para participar dos projetos) seria inverso: participariam principalmente os que tivessem maior número de ocorrências.

Comparando as duas escolas, pode-se afirmar que o projeto na instituição central não toma o tempo de aula dos alunos, enquanto na outra é desenvolvido durante o horário de aula, prejudicando o tempo destinado à apropriação dos conteúdos, distanciando esses alunos da possibilidade de compreender as reais causas da violência, que são estruturais. Não se pretende desmerecer a importância das soluções buscadas pelas escolas, mas apontar a insuficiência, sobretudo quando é realizado no período letivo, que deve servir para a profunda compreensão dos elementos que a compõem.

Não se pretende falar contra o respeito, - amor ou a amizade, mesmo porque é exatamente em nome desses sentimentos que um esforço deve ser feito, no sentido da superação da sociedade de classes. Por outro lado, o respeito pode ser o "respeito pelas grandes propriedades", o amor e a amizade somente pelos propósitos individualistas.

Por isso, é mais importante que a escola ensine profundamente as razões materiais, portanto históricas, da exclusão, do preconceito e da violência, do que ocupar o seu tempo, energia e recursos ensinando "valores" de forma isolada e que podem servir a interesses antagônicos.

Tanto no sistema de avaliação como na competição e na impossibilidade de todos os alunos participarem desse momento da escola, fica evidente a exclusão. Nesse caso, pode-se afirmar que é também ensinado que privilégios são para poucos, que só os melhores vencem, e sem o devido esclarecimento do porquê eles são "melhores". Tal princípio é possivelmente herança do liberalismo, que afirmava que todos são iguais e têm direitos iguais, no entanto, desconsiderava as condições materiais do ponto de partida e do processo.

Com efeito, nem todos os alunos que têm nota baixa as têm por falta de vontade pessoal. Talvez, se tivessem oportunidade de participar de uma atividade, criassem um vínculo maior com a escola, e isso com certeza seria positivo, podendo resultar inclusive em maior aprendizagem. Todavia, vale lembrar que isso não acontece, conforme os diretores afirmaram, por falta de condições materiais e de pessoal.

Cabe ressaltar que maioria dos alunos fica excluída dessa atividade e não do trabalho realizado na sala de aula, pois esse projeto acontece fora do horário das aulas.

Com o projeto Leituras Compartilhadas, desenvolvido por uma ONG, se repete o mesmo: na escola "B", localizada na periferia, o projeto incide de maneira mais efetiva; já teve textos publicados, seu resultado vai para as paredes e as crianças sabem a sua origem, participam. A diretora, enquanto fala do projeto, demonstra o quanto o acha importante.

Já na escola "A", a mais central, o projeto não chega aos alunos. A professora, como a maioria dos que já participaram, gosta de frequentar o assessoramento, que oferece condições de trabalho dignas: lanche, almoço, suco, café à vontade, um banheiro limpo e bem equipado, material. No entanto, o trabalho desenvolvido para incentivo à leitura na escola é realizado por outra professora, que não frequenta os 
assessoramentos oferecidos pela referida ONG. O projeto é feito da seguinte maneira: ao longo do ano, adota-se um livro e, a partir da sua leitura, são trabalhados elementos do texto, o contexto, enfim, o livro todo, e não pequenos textos de fácil compreensão, que são importantes, mas não suficientes: o ideal seria adotar textos em que a mediação do professor fosse indispensável.

A produção de texto e literatura são conteúdos de Português, e o projeto Leituras Compartilhadas tem dado auxílio de material e sugestões de textos; mas o fato de isso vir de uma ONG e alheia ao contexto da educação nos remete mais uma vez à formação do professor. Tivesse ele sido muito bem formado, não seria necessário um "curso" para desenvolver um "bom trabalho". Quanto à diversificação de material e palestras oferecidas pela ONG, é uma clara demonstração de que cada vez mais o chamado "terceiro setor" tem assumido o que é obrigação do Estado, sem que para isso possuam efetivamente uma concepção de educação pública voltada aos interesses sociais e políticos das maiorias.

Um dos possíveis motivos para existência das ONGs e empresas com projetos nas escolas é político e ideológico, pois retira e esvazia a dimensão da universalidade do sujeito em relação a sua atuação na sociedade. Tal perspectiva leva o aluno a aprender a agir e pensar de forma fragmentada, no sentido de agir imediatamente e pontualmente, deixando de ser sujeito e passando a fazer parte de um contexto sem história.

A atuação das ONGs nas escolas, e em outros setores públicos, é recomendação do Banco Mundial para educação, conforme consta no documento do banco, de 1995, intitulado

\section{"Prioridades y Estratégias para La Educacion":}

En el contexto de la diversificación del suministro de educación, el Gobierno de Bangladesh ha reconocido el papel que las ONG pueden desempeñar como complemento de sus esfuerzos para ampliar el aceso y mejorar la calidade de la educación de los niños. Las ONG sedesempeñan ya una función a nível nacional em Bangladessh en los programas de salud y población (1995.p.100).

Ainda que a recomendação acima não seja especificamente para o Brasil, as recomendações do Banco Mundial não se diferenciam muito dela quando destinadas aos países do Terceiro Mundo.
No projeto de representatividade, proposto pela mantenedora, a diferença entre as duas escolas se repete. Na escola da periferia o projeto é realizado na íntegra, com fotos, exposição de trabalhos, tudo conforme a recomendação da proponente, que idealizou e coordena o projeto. Já na escola central, foi possível perceber que há a eleição de representantes, e se realizam as atividades desse projeto de forma que a relação da escola com a mantenedora não seja prejudicada, mas se toma o menor tempo possível com ele. E, a exemplo dos outros projetos, esse não tem demonstrado apontar para uma formação com vistas à superação da democracia representativa.

Nas duas escolas investigadas foi possível perceber diferenças e semelhanças, mas o que chama mais atenção são as desigualdades.

Constatam-se os mesmos problemas, e nem poderia ser diferente, já que os determinantes encontram-se no contexto social em que estão inseridas. No entanto, mesmo os problemas sendo idênticos, se considerados da perspectiva da narração dos diretores entrevistados, o que muda, reafirma-se, é a profundidade com que tais problemas se apresentam nas duas escolas pesquisadas.

Da mesma forma, os projetos - ambas as escolas têm os três projetos - variam quanto à intensidade com que incidem no trabalho em sala de aula; é muito maior na escola em que é também maior a gravidade dos problemas, como violência, desemprego, uso de drogas, alcoolismo, fome, falta de roupas, material, de professores, entre outros.

Embora no material do projeto de Representatividade e nas reuniões sobre esse projeto a mantenedora insista na participação, na luta contra o autoritarismo e arbitrariedade, quando os professores lutam para não perderem seus direitos conquistados historicamente, como avanço na carreira, licença para qualificação, ou reposição salarial, são tratados de forma autoritária e arbitrária. Um exemplo: a bandeira maior desse projeto é a formação do Conselho Municipal de Educação, que não é paritário e cujo presidente é indicado pelo prefeito.

Outra organização incentivada é a formação dos conselhos escolares. Esta é uma iniciativa 
de incremento da participação da comunidade na escola, porém as condições de formar a comunidade escolar para que participe em condições efetivas não são dadas, e a participação da comunidade não pode eliminar as obrigações do poder público para com as escolas. Incide sobre este projeto a visão de "participação" e "autonomia", muito mais como participação na execução do que na efetiva participação decisória e política.

\section{Considerações finais}

Foi possível constatar nas escolas e na aplicação dos projetos que, à medida que os efeitos do neoliberalismo crescem e se traduzem na organização - ou desorganização - do trabalho na escola, cresce também a impossibilidade de se ensinar de fato o que precisa ser ensinado: o conhecimento acumulado pelo ser humano ao longo da história.

Entre os inúmeros problemas que se pode encontrar na escola, destacam-se: a insuficiência da formação dos professores, o excesso de trabalho, a falta de condições materiais, as classes superlotadas, as instalações que deixam a desejar. Grande parte dos alunos assume tarefas domésticas, como cuidar dos irmãos menores, e tenta ganhar algum dinheiro realizando pequenos (às vezes grandes) trabalhos; outros não conseguem nem mesmo frequentar as aulas, pelos mesmos motivos, ou simplesmente pela falta da presença de um adulto que o supervisione (porque este trabalha o dia todo para garantir o sustento da família). Alguns preferem fazer o que é mais fácil e normal para sua idade: brincar.

Obviamente, não ocorre a ninguém negar aos alunos o direito de brincar, mas nesses casos o que preocupa é escolherem sozinhos onde brincam, do quê brincam e com quem brincam.

Isso posto, pode-se reafirmar e repetir que quanto mais visíveis os efeitos do neoliberalismo no interior e nas imediações das escolas pesquisadas, mais se recorre à proposição de projetos com diferentes objetivos, seja porque atendem a uma necessidade pontual e imediata, seja porque simplesmente mantêm os alunos professores em sala de aula sabendo o que estão fazendo e por que estão agindo, ao menos naquele momento. Esses projetos - Leituras Compartilhadas, Representatividade de Valores aparecem como alternativas ideológicas ao que a escola não pode superar.

De onde se pode concluir que uma escola revolucionária hoje, para trabalhar na direção contrária à ordem vigente, ensina de fato aos seus alunos conhecimentos clássicose contemporâneos que permitam a eles compreenderem as causas e os efeitos dos problemas que hoje enfrenta a classe social a que pertencem. Para isso, é necessária também a identidade e, por consequência, a consciência de classe.

Nesse sentido se desejaria que as duas escolas pesquisadas priorizassem o conhecimento materializado historicamente em detrimento de projetos pontuais, que quando muito trabalham apenas fragmentos deste conteúdo, e muito mais na escola localizada na periferia do que a outra, porque, mesmo não sendo da forma ideal, a escola central apresentou maior tempo de período letivo empregado ao ensino do que aos projetos investigados mais detidamente. É importante registrar o imenso esforço que as duas escolas e seus trabalhadores despendem para que elas funcionem todos os dias, apesar das condições.

Importante esclarecer que não se pretende aqui estabelecer uma imagem de piedade em relação ao professor, e que em função de suas condições de trabalho toda e qualquer postura se justifica, mas sim contribuir para explicar o atual estado de precarização do trabalho docente, como acontece também com outras categorias de trabalhadores.

O discurso dos diretores entrevistados retrata que, mesmo estando a escola de posse das melhores intenções, ao não se perceber que as reais causas dos problemas estão além da própria escola, do bairro e das casas dos alunos, estão somente "conformando-se aos débeis limites do capital, pois em seu interior é impossível conciliar os interesses dos dominantes e dominados". (MÉSZÁROS, 2005, p.11)

Finalizando, a hipótese que se colocou após os primeiros passos da pesquisa empírica e bibliográfica foi que quanto mais precária é a escola, maior a aceitação e criação de projetos. 
Entretanto, tal hipótese não se confirmou. Constatou-se que a precariedade não tem relação direta com o número de projetos desenvolvidos, mas com o tempo e a profundidade com que tais projetos influenciam o trabalho pedagógico, ou seja, quanto mais precariedade, maior o tempo do trabalho escolar é destinado ao desenvolvimento de projetos, alheios ao currículo.
Este trabalho é resultado da investigação e da tentativa de se responder a essas questões, além da busca de uma contribuição para o debate educacional.

Em tempos no quais muitos afirmam o fim das certezas, reafirma-se aqui a certeza histórica da importância da escola na emancipação da classe trabalhadora.

\section{Referências Bibliográficas}

BARATA, R. B.; RIBEIRO, M. C. S. de A.; MORAES, J. C. Desigualdades sociais e homicídios em adolescentes e adultos jovens na cidade de São Paulo em 1995. Rev. bras. epidemiol., São Paulo, v. 2, n. 1-2, 1999. Disponível em: http://www.scielo.br/scielo.

DUARTE, N. Vigotski e o “Aprender a Aprender"crítica às apropriações neoliberais e pós-modernas da teoria vigotskiana. 2.ed.Campinas: Autores Associados, 2001

GRAMSCI, A. Cadernos do Cárcere. 2.ed. Rio de Janeiro. Civilização Brasileira, vol. 2, 2001.

HERNÁNDEZ, F. M. V. A organização do Currículo por projetos de trabalho.O conhecimento é um caleidoscópio. 5.ed.Porto Alegre: Artmed, 1998.

IANNI. O. Capitalismo, violência e terrorismo. Rio de Janeiro: Editora Civilização Brasileira, 2004.

LAVAL, C. A Escola não é uma empresa. O neo-liberalismo em ataque ao ensino público. Londrina: Editora Planta, 2004.

LUEDEMANN, C. S. Anton Makarenko. Vida e obra - a pedagogia na revolução. $1^{a}$ ed. São Paulo: Expressão Popular, 2002.

MESZÁROS, I. Para Além do Capital. São Paulo: Boitempo Editorial, 2002.

O século XXI: socialismo ou barbárie? São Paulo: Boitempo Editorial, 2003.

O poder da ideologia. São Paulo: Boitempo editorial, 2004.

A educação para além do capital. São Paulo: Boitempo Editorial, 2005.

A teoria da Alienação em Marx. São Paulo: Boitempo Editorial, 2006.

MONTAÑO, C. Terceiro Setor e Questão Social: crítica ao padrão emergente de intervenção social. 2.ed. São Paulo: Cortez, 2003.

BANCO MUNDIAL. Prioridades y Estratégias Para La Educacion. Estudio sectorial del Banco Mundial. Mayo 1995.

ROSSLER, J. H. Sedução e alienação no discurso construtivista. São Paulo: Autores Associados, 2006.

SANTOS, G. R. C. M. A Metodologia de Ensino por Projetos. Curitiba: IBEPEX, 2006.

SAVIANI, D. Pedagogia histórico-crítica: primeiras aproximações. 8.ed. Campinas: Autores Associados, 2003.

SNYDRES, G. Alegria na Escola. São Paulo: Manole, 1988.

SUCHODOLSKI, B. Fundamentos da Pedagogia Socialista. 3.ed. Barcelona: Editorial Laia, 1976.

TAVARES. T. M. Gestão Pública do Sistema de Ensino no Paraná (1995-2002). Tese (Doutorado em Educação). São Paulo: PUC-SP, 2004. 